\title{
Cancer-associated fibroblasts promote the survival of irradiated nasopharyngeal carcinoma cells via the NF-KB pathway
}

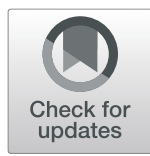

Weiqiang Huang ${ }^{1 \dagger}$, Longshan Zhang ${ }^{1 \dagger}$, Mi Yang ${ }^{1}$, Xixi Wu', Xiaoqing Wang ${ }^{1}$, Wenqi Huang ${ }^{2}$, Lu Yuan², Hua Pan', Yin Wang ${ }^{1}$, Zici Wang ${ }^{3}$, Yuting Wu${ }^{2}$, Jihong Huang ${ }^{2}$, Huazhen Liang ${ }^{4}$, Shaoqun Li ${ }^{5}$, Liwei Liao ${ }^{1}$, Laiyu Liu ${ }^{2 *}$ and Jian Guan ${ }^{1 *}$

\begin{abstract}
Background: Irradiation has emerged as a valid tool for nasopharyngeal carcinoma (NPC) in situ treatment; however, NPC derived from tissues treated with irradiation is a main cause cancer-related death. The purpose of this study is to uncover the underlying mechanism regarding tumor growth after irradiation and provided potential therapeutic strategy.

Methods: Fibroblasts were extracted from fresh NPC tissue and normal nasopharyngeal mucosa. Immunohistochemistry was conducted to measure the expression of a-SMA and FAP. Cytokines were detected by protein array chip and identified by real-time PCR. CCK-8 assay was used to detect cell proliferation. Radiationresistant (IRR) 5-8F cell line was established and colony assay was performed to evaluate tumor cell growth after irradiation. Signaling pathways were acquired via gene set enrichment analysis (GSEA). Comet assay and $y-H 2 A X$ foci assay were used to measure DNA damage level. Protein expression was detected by western blot assay. In vivo experiment was performed subcutaneously.
\end{abstract}

Results: We found that radiation-resistant NPC tissues were constantly infiltrated with a greater number of cancerassociated fibroblasts (CAFs) compared to radiosensitive NPC tissues. Further research revealed that CAFs induced the formation of radioresistance and promoted NPC cell survival following irradiation via the IL-8/NF-KB pathway to reduce irradiation-induced DNA damage. Treatment with Tranilast, a CAF inhibitor, restricted the survival of CAFinduced NPC cells and attenuated the of radioresistance properties.

Conclusions: Together, these data demonstrate that CAFs can promote the survival of irradiated NPC cells via the NF-KB pathway and induce radioresistance that can be interrupted by Tranilast, suggesting the potential value of Tranilast in sensitizing NPC cells to irradiation.

Keywords: Nasopharyngeal carcinoma, Cancer-associated fibroblast, Irradiation, IL-8, NF-kB pathway, Tranilast

\footnotetext{
*Correspondence: liuly5461@163.com; guanjian5461@163.com

†'Weiqiang Huang and Longshan Zhang contributed equally to this work.

${ }^{2}$ Chronic Airways Diseases Laboratory, Department of Respiratory and Critical

Care Medicine, Nanfang Hospital, Southern Medical University, Guangzhou,

Guangdong, China

'Department of Radiation Oncology, Nanfang Hospital, Southern Medical

University, Guangzhou, Guangdong, China

Full list of author information is available at the end of the article
}

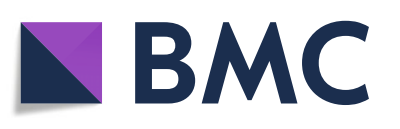

(- The Author(s). 2021, corrected publication 2021. Open Access This article is licensed under a Creative Commons Attribution 4.0 International License, which permits use, sharing, adaptation, distribution and reproduction in any medium or format, as long as you give appropriate credit to the original author(s) and the source, provide a link to the Creative Commons licence, and indicate if changes were made. The images or other third party material in this article are included in the article's Creative Commons licence, unless indicated otherwise in a credit line to the material. If material is not included in the article's Creative Commons licence and your intended use is not permitted by statutory regulation or exceeds the permitted use, you will need to obtain permission directly from the copyright holder. To view a copy of this licence, visit http://creativecommons.org/ licenses/by/4.0/. The Creative Commons Public Domain Dedication waiver (http://creativecommons.org/publicdomain/zero/1. 0/) applies to the data made available in this article, unless otherwise stated in a credit line to the data. 


\section{Background}

$\mathrm{NPC}$ is an Epstein-Barr virus (EBV)-associated cancer, prevalent in southeast Asia and north Africa [1]. According to the statistics published in 2018, cancer arising from the nasopharynx is responsible for 129,079 cases and 72,987 deaths each year [2]. Despite the early detection and advances in radiotherapy, treatment for patients who partially responded to irradiation continue to be unsatisfactory primarily due to the acquisition of radioresistance and tumor recurrence following irradiation [3, 4]. However, the underlying mechanisms remain elusive.

The tumor microenvironment (TME) consists of stromal cells, including fibroblasts, macrophages, endothelial cells, other immune cells, extracellular matrix, as well as the bioactive substances secreted by these cells [5]. As one of the most predominant stromal cell subtypes in solid tumors, cancer-associated fibroblasts (CAFs) contribute to most aspects of cancer progression, including proliferation, migration, invasion, angiogenesis, induction of chemoresistance and escape from immunemediated killing [6-8]. It has been reported that CAFs can enhance cervical tumor growth after irradiation and promote the epithelial mesenchymal transition of pancreatic tumors via crosstalk between tumor cells and CAF-like vascular endothelial growth factors (VEGF) and fibroblast growth factors (FGF) $[9,10]$. Radiobiological research has shown that the relationship between NPC and CAFs remains poorly understood. Recently, immune checkpoint inhibitors have emerged at the frontier in anticancer research for patients with recurrent or metastatic head and neck cancer following irradiation treatment $[11,12]$. Although several breakthroughs have been made, the total efficacy of immunotherapy is finite. Tranilast is a CAF inhibitor [13] that has been reported to suppress CAF proliferation and inhibit the adverse effects induced by CAFs within the immune microenvironment [14]. For example, it has been reported that Tranilast treatment was associated with a reduced level of transforming growth factor- $\beta 1$ production by CAFs. However, the precise mechanism by which Tranilast suppresses CAF activity in irradiation-related research remains unknown.

Our research has found that CAFs can activate the NF- $\mathrm{kB}$ pathway in irradiated NPC cells to reduce DNA damage, which could be interrupted by tranilast. These findings suggest that Tranilast may have potential value in increasing tumor sensitivity to irradiation. Thus, the latent function of Tranilast in NPC warrants further investigation in the future.

\section{Materials and methods}

\section{Cell culture and regents}

The human NPC cell lines, 5-8F, 6-10B, and HK-1 were donated by the Sun Yat-sen University Cancer Center.
Cells were cultured in 1640 medium (Gibco) supplemented with $10 \%$ FBS (Gibco) and 1\% penicillin/streptomycin (Thermo Scientific). Human CAFs and normal fibroblasts (NFs) were extracted from fresh NPC tissues and matched to normal nasopharynx tissues from patients diagnosed with local recurrence NPC patients treated with radical radiotherapy previously. Fibroblast isolation was performed as previously described [15]. Briefly, fresh tissues were cut into pieces of 2 to $3 \mathrm{~mm}$ and cultured in high-glucose DMEM medium (Gibco) for approximately one week until fibroblasts appeared. $\alpha$-SMA was used to identify CAFs and NFs as described [6]. Specimens were obtained with written informed consent from patients with NPC enrolled at Nanfang Hospital, Southern Medical University. Characteristics of 4 CAF donors were documented in supplementary Table 1. In functional studies, NFs and CAFs were used within 10 passages. All cells were cultured in a humidified incubator containing $5 \% \mathrm{CO}_{2}$ at $37^{\circ} \mathrm{C}$.

Human recombinant IL-8, HGF, and TNF- $\alpha$ were purchased from Peprotech (Suzhou, China). An antagonist of IL-8 receptor (Repertaxin), inhibitor of NF- $\mathrm{kB}$ activation (caffeic acid phenethyl ester [CAPE]), and a lactate inhibitor (sodium dichloroacetate, DCA) were purchased from Selleck Chemicals (Houston, USA); Tranilast was purchased from Target Mol (Massachusetts, USA).

\section{Establishment of radiation-resistant (IRR) 5-8F IRR cells}

Establishment of IRR cell lines was performed as previously described [16]. In brief, cells were treated twice with irradiation at a graded dose of 2, 4, 6, 8 and $10 \mathrm{~Gy}$, respectively. A total IR dose of $60 \mathrm{~Gy}$ was administered with the entire selection procedure. The final surviving 5-8F cells were verified, defined as radioresistant 5-8F cells, and termed 5-8F IRR. The parental 5-8F cells were treated without irradiation. Cells within 10 passages were used for experiments once the 5-8F-IRR cells were successfully established.

\section{Cell viability assay}

CAFs were subjected to a cell viability assay using Cell Counting Kit-8 (Dojindo, Japan) according to the manufacturer's instructions. In brief, CAFs were cultured in medium containing Tranilast at a concentration of $200 \mu \mathrm{M}$ and $400 \mu \mathrm{M}$, respectively for two days and subsequently cultured at the density of $1.5 \times 10^{3}$ cells per well in triplicate in 96-well plates containing Tranilastfree medium. After culturing for $8 \mathrm{~h}, \mathrm{CAFs}$ were applied to CCK- 8 assay and a subsequent detection was performed at the indicated time points. To detect the impact of Repertaxin and CAPE on NPC cell line proliferation, cells were cultured in medium containing a wide-range of reagent concentrations $(0.01,0.1,1,10$, 
and $100 \mu \mathrm{M}$ for CAPE and 1, 10, $40 \mu \mathrm{M}$ for Repertaxin) for $2-4$ days and then subjected to a CCK- 8 assay.

\section{Colony forming assay}

A total of $5-8 \mathrm{~F}, 6-10 \mathrm{~B}$, and $\mathrm{HK}-1$ cells were cultured in six-well plates for $12 \mathrm{~h}$ at various densities according to the aim of each experiment. The cell density was listed as follows: 300 (0 Gy), 400 (2 Gy), 1000 (4 Gy), 2000 (6 Gy), 4000 (8 Gy) per well for 5-8F and 6-10B and 500 (2 Gy), 10,000 (8 Gy) per well for HK-1. After a 2-week incubation, the six-well plates were obtained and colonies with more than 50 cells were counted. The surviving fraction (SF) was estimated using the following formula: $\mathrm{SF}=$ (number of colonies formed/number of cells seeded $x$ plating efficiency of the control group), where plating efficiency was calculated as the ratio between colonies observed and the number of cells plated. Dose-response colony survival curves were plotted accordingly.

\section{Cytokine assay}

CAF and NF cells were cultured in serum-free medium when grown to $80 \%$ confluence. After incubating for two days, the medium was collected and concentrated before dialysis. After labeling with biotin, the samples were applied to an antibody array chip (R\&D; Cat ARY022B, LabEx) overnight. The following day, the chips were reacted with streptavidin-conjugated fluorescence dye, and detected with a chemiluminescence imager (Chemi Scope 6300). Data were normalized to the total protein.

\section{RNA sequencing and tissue microarray}

Total RNA of parent 5-8F and 5-8F IRR cells were extracted using TrIzol reagent (Invitrogen Life Technologies, CA) according to the manufacturer's instructions. The prepared RNA was then subjected to sequencing on a BGISEQ-500 platform at Beijing Genomics Institution (www.genomics.org.cn, BGI, Shenzhen, China). The level of gene expression was quantified and the NOISeq method was performed to screen for differentially expressed genes (DEGs) as previously described [17]. A tissue microarray was conducted by Shanghai Biotechnology Corporation using Affymetrix Genechip according to manufacturer's protocol [18].

\section{Radiosensitivity index (RSI) analysis and gene set enrichment analysis}

An RSI index served as an indicator for radiosensitivity, and was calculated as previously described [19]. In brief, head and neck squamous carcinoma (HNSCC) patients in the TCGA database and NPC patients in the GSE12542 dataset were divided into two groups based on the median of CAFs score using an online tool (https://gfellerlab.shinyapps.io/EPIC_1-1/). Following Racle's study, 20 markers were used to identify CAFs
[20]. Gene Set Enrichment Analysis (GSEA) software version 3.0 (Broad Institute, USA) was used to analyze GSE48501 and a human microarray containing radioresistant and radiosensitive NPC samples. A threshold of $P \leq 0.05$ was applied for the analysis. Data for GSE48501 and GSE12542 were downloaded from the NCBI Gene Expression omnibus (GEO, http://www.ncbi.nlm.nih. gov/geo/).

\section{Lactate detection}

Lactate was detected using a lactic acid measurement kit (Junji Biotechnology Co, China) according to the manufacturer's protocol. Briefly, blank medium and conditioned medium produced by NFs and CAFs were prepared and subjected to a chromogenic reaction with the indicated reagents. The absorbance value was detected by a microplate reader machine (BIO-RAD 689). Data were normalized to the lactate standards.

\section{Comet assay}

A comet assay was performed using a DNA Damage Detection Kit (Keygen, China). The cells were irradiated as described at dose of $2 \mathrm{~Gy}$ and treated in accordance with the experimental design. The following day, cells were harvested and suspended in PBS containing 1\% lowmelting agarose and layered onto adhesive microscope slides previously covered with $0.5 \%$ normal-melting agarose. The cells were dipped in a specific lysed buffer at $4{ }^{\circ} \mathrm{C}$ for $2 \mathrm{~h}$. Next, the DNA was uncoiled and unwound in an alkalescent electrophoresis buffer for 30 min. Electrophoresis was performed and the cells were stained with 4',6-diamidino-2-phenylindole (DAPI) solution for $10 \mathrm{~min}$ in a dark room. The slides were examined with an Eclipse fluorescence microscope (Nikon, Japan). Analysis of comet assay was performed as described [21].

\section{Real-time quantitative PCR}

Total RNA was extracted from CAFs using TrIzol reagent (Invitrogen Life Technologies, CA) as instructed by the manufacturer's protocol. SuperScript III FirstStrand Synthesis SuperMix (Thermo Fisher Scientific, MA) was used for reverse transcription according to the manufacturer's protocol. Real-time quantitative PCR (qRT-PCR) was implemented to measure specific mRNA expression using an ABI7500 FAST system with TaqMan Reverse Transcription Reagents and SYBR Green PCR MasterMix (Applied Biosystems, CA, USA). GAPD $\mathrm{H}$ was used as a loading control. The specific primers were listed as follows: GAPDH, forward: 5' -GGAG CGAGATCCCTCCAAAAT-3' and reverse: 5'-GGCT GTTGTCATACTTCTCATGG-3'. IL-8, forward: 5'GTGCAGTTTTGCCAAGGAGT-3' and reverse: 5' CTCTGCACCCAGTTTTCCTT-3'. HGF: forward: 5'- 
TGGGCCATTCTATTCCCCC-3' and reverse: 5'CATGGGGTCAAGCTTCCAGT- $3{ }^{\prime}$. The ${ }^{\circ}$ Ct expression values for amplification were calculated by normalizing to an internal control.

\section{Conditioned medium derived from human NFs and CAFs} CAFs and matched non-malignant NFs were cultured in $25 \mathrm{~mL}$ culture flask with high-glucose DMEM (Gibco) supplemented with 10\% FBS at same density overnight, respectively. The cells were refreshed with serum-free DMEM and the supernatants were harvested after $48 \mathrm{~h}$. Next, the cell pellet was removed after centrifugation and the conditioned medium $(\mathrm{CM})$ was acquired and stored at $-80^{\circ} \mathrm{C}$ for future experimentation.

\section{Western blotting analysis}

Cells were lysed with RIPA lysis buffer (Beyotime, Shanghai, China) supplemented with phosphatase and a protease inhibitor cocktail (Roche). The proteins were subjected to $10 \%$ SDS-PAGE followed by transfer to PVDF membrane and subsequent incubation with specific primary antibodies at $4{ }^{\circ} \mathrm{C}$ overnight. Membranes were then incubated with respective secondary antibodies (FuDe, China) for $1 \mathrm{~h}$ at room temperature. The primary antibodies included mouse monoclonal antiGAPDH (60004-1-IG, Proteintech, USA), rabbit monoclonal anti- $\alpha$-SMA (ab124964, Abcam, USA), rabbit monoclonal p65 (8242, CST, USA), rabbit monoclonal p-p65 (3039, CST, USA), mouse monoclonal IKB- $\alpha$ (4841, CST, USA), and rabbit monoclonal $\gamma$-H2AX (9718, CST, USA). GAPDH was used as an internal reference.

\section{Immunofluorescence}

Cells were seeded into a confocal dish and incubated overnight. The cells were washed three times with phosphate buffered saline (PBS) and fixed with $4 \%$ paraformaldehyde for $10 \mathrm{~min}$. Next, $0.5 \%$ Triton X-100 was used for permeabilization and the samples were blocked with goat serum albumin. Subsequently, cells and tissues were incubated with primary antibodies targeted to $\alpha$ SMA (1:400) and (or) rabbit monoclonal IL-8 (60004-1IG, Proteintech, USA) at concentration of 1:100 or $\gamma$ $\operatorname{H2AX}(1: 200)$ at $4{ }^{\circ} \mathrm{C}$ overnight, followed by an incubation with an anti-rabbit Alexa fluor-594-conjugated and (or) anti-rabbit Alexa fluor-488-conjugated secondary antibody, respectively. The nuclei were stained with 4 , 6-diamidino-2-phenylindole (DAPI), and images were observed with an Eclipse fluorescence microscope (Nikon, Japan). Expression of $\alpha$-SMA and IL-8 were determined by mean fluorescence intensity. Analysis of nuclear $\gamma-\mathrm{H} 2 \mathrm{AX}$ foci was performed as described [21].

\section{IL-8 RNA knockdown in CAFs}

A knockdown of IL-8 in CAFs was performed using small interfering RNA (siRNA) (RIBOBIO, China) with Lipofectamine 2000 (Invitrogen, CA) for $10 \mathrm{~h}$ of transfection. The specific sequence targeting IL-8 was listed as follows: GCCAAGGAGTGCTAAAGAA.

\section{Patients and clinical samples}

All patients were treated with intensity-modulated radiation therapy with a radical dose ranging from $60 \mathrm{~Gy}$ to 70 Gy. Radioresistance was defined as the local relapse or recurrence of the ever irradiated area after 6 months of radiotherapy via enhanced computed tomography or enhanced magnetic resonance imaging [11]. Human NPC samples were obtained from Nanfang Hospital, Southern Medical University, including 6 cases of radioresistant tissues and 16 cases of radiosensitive tissues. The collection of clinical samples for research was approved by the Ethics Committee of the Nanfang Hospital.

\section{Immunohistochemistry assay}

Each of the staining processes were conducted according to the manufacturer's protocol. Primary antibodies consisted of rabbit monoclonal anti- $\alpha$-SMA (ab124964, Abcam, USA) at a dilution of 1:400 and FAP (ab207178, Abcam, USA) at the dilution of 1:100. The levels of $\alpha$ SMA and FAP expression were evaluated based on the staining intensity and percentage of positively-stained CAFs. Final scores were assessed as the total evaluation of staining intensity ( 0 for negative, 1 for weak, 2 for moderate and 3 strong) plus percent positivity ( 0 for $0 \%$, 1 for $1 \%-25 \%, 2$ for $26 \%-50 \%, 3$ for $>50 \%$ ) [22]. The IHC evaluation was performed by two independent pathologists [23].

\section{Mouse irradiation assays}

Three-week-old male BALB/c nude mice were purchased from Southern Medical University Laboratory Animal Center (Guangzhou, China). Experiments involving animals were approved by the Institutional Animal Care and Use Committee of the Southern Medical University. Mouse models were generated by a subcutaneous inoculation of 5-8F cells alone or combined with human cancer-associated fibroblasts at a 1:1 ratio. The number of cancer cells in each injection was $1 \times 10^{6}$ for one flank side. Mice were divided into six groups as required and received irradiation treatment at a $8 \mathrm{~Gy} \times 3$ schedule 9 days after injection [24, 25]. Before irradiation, one co-injection group was subjected to an orthotopic injection of $200 \mu \mathrm{M}$ Tranilast in $100 \mu \mathrm{L}$ daily for three days [13]. The tumor volume was determined at the indicated time points with the following formula: tumor volume $\left(\mathrm{mm}^{3}\right)=1 / 2 \times$ longest diameter $2 \times$ shortest 
diameter. Mice were sacrificed and the tumors were excised after 2 weeks of the first irradiation. Treatment of irradiation was given at a dose rate of $500 \mathrm{cGy} / \mathrm{min}$ with a linear accelerator (Varian 2300EX, Varian, Palo Alto, CA) that generated $6 \mathrm{MV} \mathrm{X}$-ray.

\section{Statistical analysis}

Statistical analysis of the data was performed using SPSS software version 20.0. Both paired and unpaired $t$-tests were performed to analyze the data between two experimental groups. Mann-Whitney tests were used to calculate the $P$ values for IHC staining quantification. Data were presented as the means \pm standard deviation (SD). Statistical significance was defined as a $P$-value less than 0.05. ${ }^{*} P<0.05 ;{ }^{* * *} P<0.01 ;{ }^{* * * *} P<0.001 ;{ }^{* * * * *} P<0.0001$; ns, no significance.

\section{Results}

\section{CAFs induce radioresistance of NPC cells}

Clinically, surgical resected radiation-resistant NPC tissues are stiff, which was also aligned with the findings of the physical examination, suggesting an abundance of stromal elements within the tissues. To uncover the role of CAFs in cancer irradiation treatment, patients with HNSCC in the TCGA dataset and NPC patients in the GSE12452 dataset were grouped based on the degree of CAF infiltration and the index of RSI was calculated. Consequently, patients with abundant CAF infiltration attained a higher RSI score (Fig. 1a and b), representing a lower sensitivity to irradiation. Furthermore, pathological analysis demonstrated that tissues from radiation-resistant carcinoma were infiltrated with substantial CAFs (Fig. 1c) that stained positive for $\alpha$-SMA and FAP when compared with radiosensitive NPC (Fig. $1 \mathrm{~d}$ and e; Fig. S1a and b). To date, little is known regarding the potential function of CAFs in assisting the acquisition of radioresistance for NPC. Thus, whether tumor cells surviving irradiation will acquire radioresistance characteristics following stimulation with $\mathrm{CAF} / \mathrm{CM}$ remain unclear. To this end, we extracted and identified fibroblasts from the NPC tissues (Fig. If and g; Fig. S1c) and subsequently cultured the NPC cell lines with CM from CAFs or matched NFs following exposure of tumor cells to irradiation as illustrated (Fig. 1h). A colony assay demonstrated that the cells cultured with $\mathrm{CAF} / \mathrm{CM}$ survived more the under higher given dose of 8Gy (Fig. 1i and $\mathrm{j}$ ). These findings suggest that CAFs can induce radioresistance of NPC after adequate stimulation.

\section{CAFs secrete IL-8 to promote NPC cell survival upon irradiation exposure}

Next, we found that carcinoma cells supported with CAF/CM exhibited enhanced survival following 2Gy dose of irradiation compared with the group incubated with CM from NFs (Fig. 2a and b). Previous studies have suggested that CAFs secrete a variety of bioactive substances that contribute to tumor progression [26-28]. Moreover, CAFs were reported to produce a substantial amount of cytokines and generate an inflammatory environment for solid tumors [29]. Thus, a cytokine array was performed to understand the latent cytokines responsible for the enhanced survival and proliferation of irradiated NPC cells. By detecting CM production by CAFs, we found that interleukin 8 (IL-8) was substantially elevated compared with NF-derived CM, which was verified via RT-qPCR (Fig. 2c and d). Further study suggested that CAFs secreted IL-8 which was higher in radioresistant NPC tissues (Fig. 2e and f). Next, a functional assay showed that the addition of IL-8 contributed to the increased survival of irradiated cancer cells (Fig. S2a and b). Although the level of hepatocyte growth factor (HGF) was also promoted and was testified (Fig. 2c; Fig. S2c), the addition of HGF failed to significantly improve cell recovery (Fig. S2d and e). An interruption of IL-8 signaling by a knockdown of IL-8 (Fig. S2f - h) or the addition of an IL-8 receptor antagonist (Fig. S3a; Fig. $2 \mathrm{~g}$ and $\mathrm{h}$ ) was found to restrict the survival of cancer cells promoted by CAFs after irradiation.

A Warburg effect was reported to create a more advantageous TME by increasing the tumor metastatic potential with a high level of lactate, and thereby enhance resistance to treatment $[30,31]$. Critically, CAFs have emerged as a producer of a large amount of intermediate metabolites (e.g., lactate) that modulate glycolysis activity in HNSCC [6]. Intermediate metabolites produced by CAFs have been reported to enhance the proliferation of irradiated tumor cells [13]. Therefore, lactate production by CAFs in the supernatant was investigated. Although a difference was observed (Fig. S3b), the addition of a lactate production inhibitor failed to lead to an obvious impact on the survival of cancer cells which was consistent with previous research [13] (Fig. S3c and d).

\section{CAFs activate the NF-кB pathway in irradiated NPC cells}

Tumor cells fed with CAF/CM exhibited increased proliferation and radioresistance properties after irradiation. To further uncover the underlying signaling pathways involved, an NPC tissue microarray and GSE48501 dataset containing radioresistant tissues and cell lines, respectively were analyzed using GSEA software. Given the circumstances, the NF- $\kappa B$ pathway was both substantially up-regulated in radioresistant NPC tissues and cell lines (Fig. S4a - c). Differential expression genes of tissues were shown in supplementary material. Next, we established a radiation-resistant NPC 5-8F cell line and determined the sensitivity to irradiation compared to the parental 
a

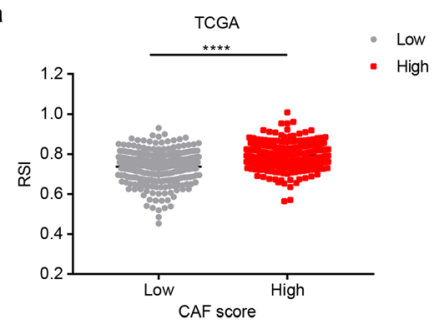

b
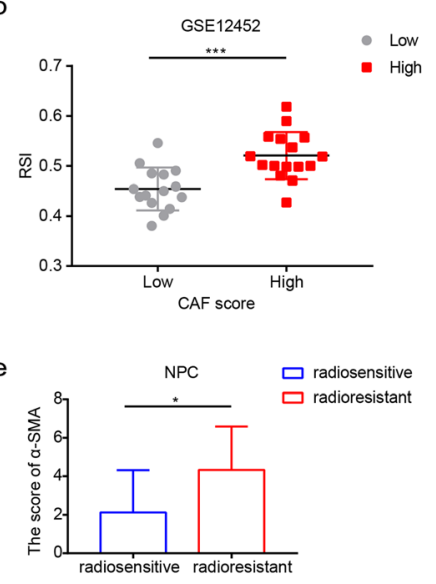

f

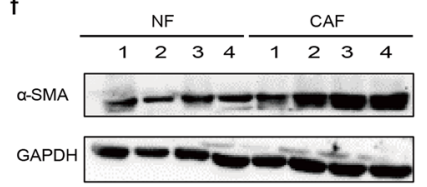

h

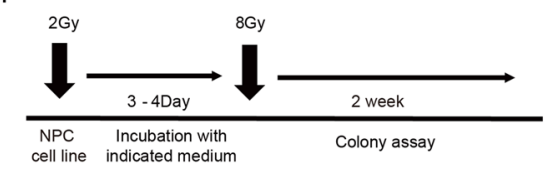

NF c

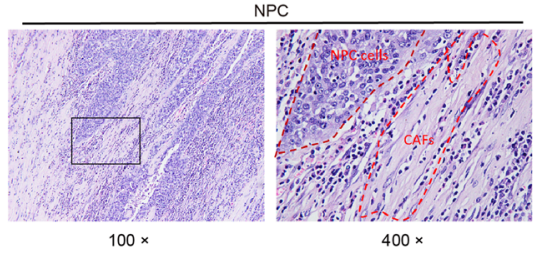

d
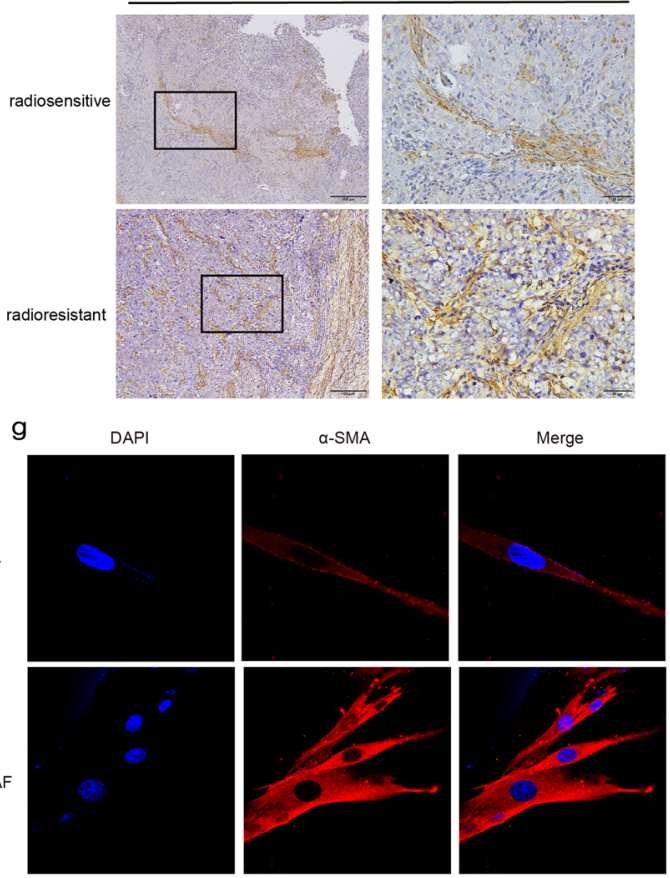

i
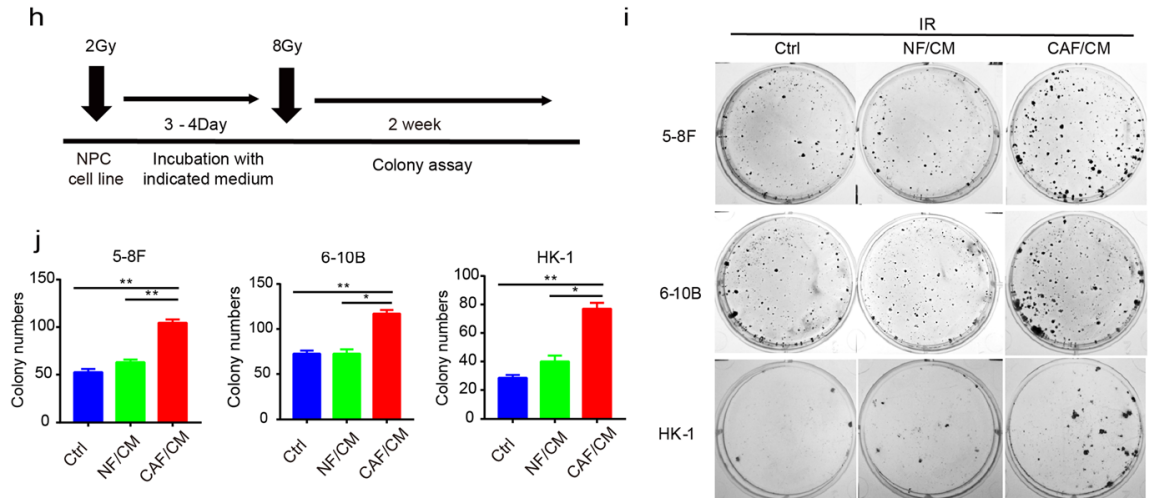

Fig. 1 CAFs induced radioresistance of tumor cells. $\mathbf{a}$ and $\mathbf{b}$ RSI scores of tumors with abundant CAF infiltration were higher than the group with Iow CAF infiltration based on TCGA database and GSE12452 dataset, respectively. c HE staining showed the infiltration of CAFs in NPC tissue. d and $\mathbf{e} \mathrm{HC}$ showed greater CAF infiltration in radioresistant NPC tissue. $\mathbf{f}$ and $\mathbf{g}$ Western blot and immunofluorescence assay showed that CAFs expressed higher levels of a-SMA than NFs. h-j CAFs induced radioresistance of NPC cells. ${ }^{*} P<0.05 ;{ }^{* *} P<0.01$; ${ }^{* * *} P<0.001$; ${ }^{* * *} P<0.0001$, ns, no significance

cells (Fig. S4d and e). A transcription sequencing analysis was conducted and showed that the NF-kB pathway was also activated in $5-8 \mathrm{~F}$ cells when acquiring radioresistance properties (Fig. S4f). In addition, protein levels of phosphorylated p65 involved in this pathway was also up-regulated (Fig. S4g). Consistently, the NF- $\mathrm{B}$ pathway was activated with promoted protein levels of phosphorylated p65 subunit and decreased expression of IKB- $\alpha$ in tumor cells post-irradiation following the addition of $\mathrm{CM}$ from CAFs (Fig. 3a). Interruption of the IL-8 signaling pathway inhibited NF- $\mathrm{kB}$ signaling pathway activation with decrease of phosphorylated p65 protein expression in irradiated tumor cells (Fig. 3b). Following 

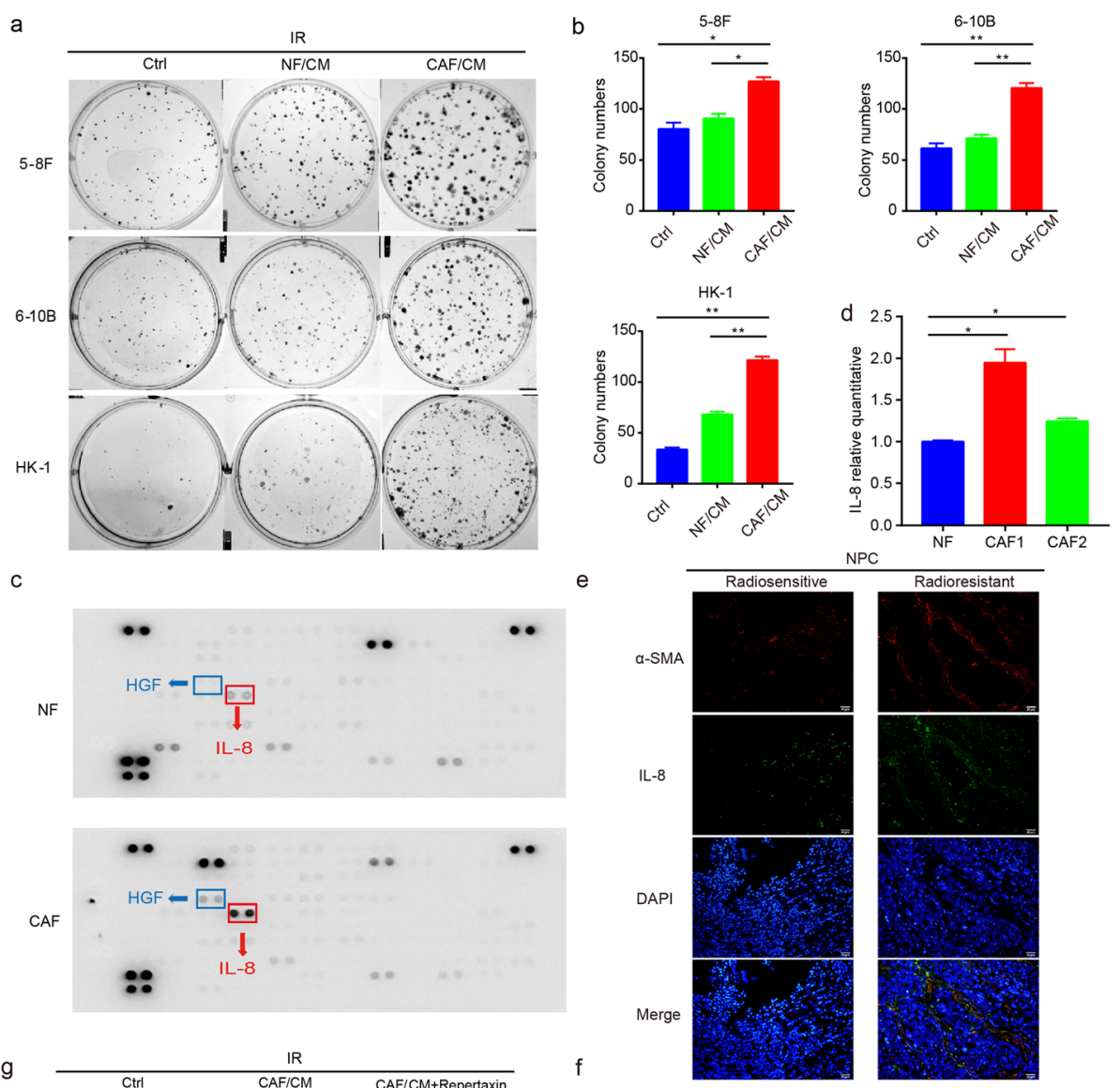
NPC
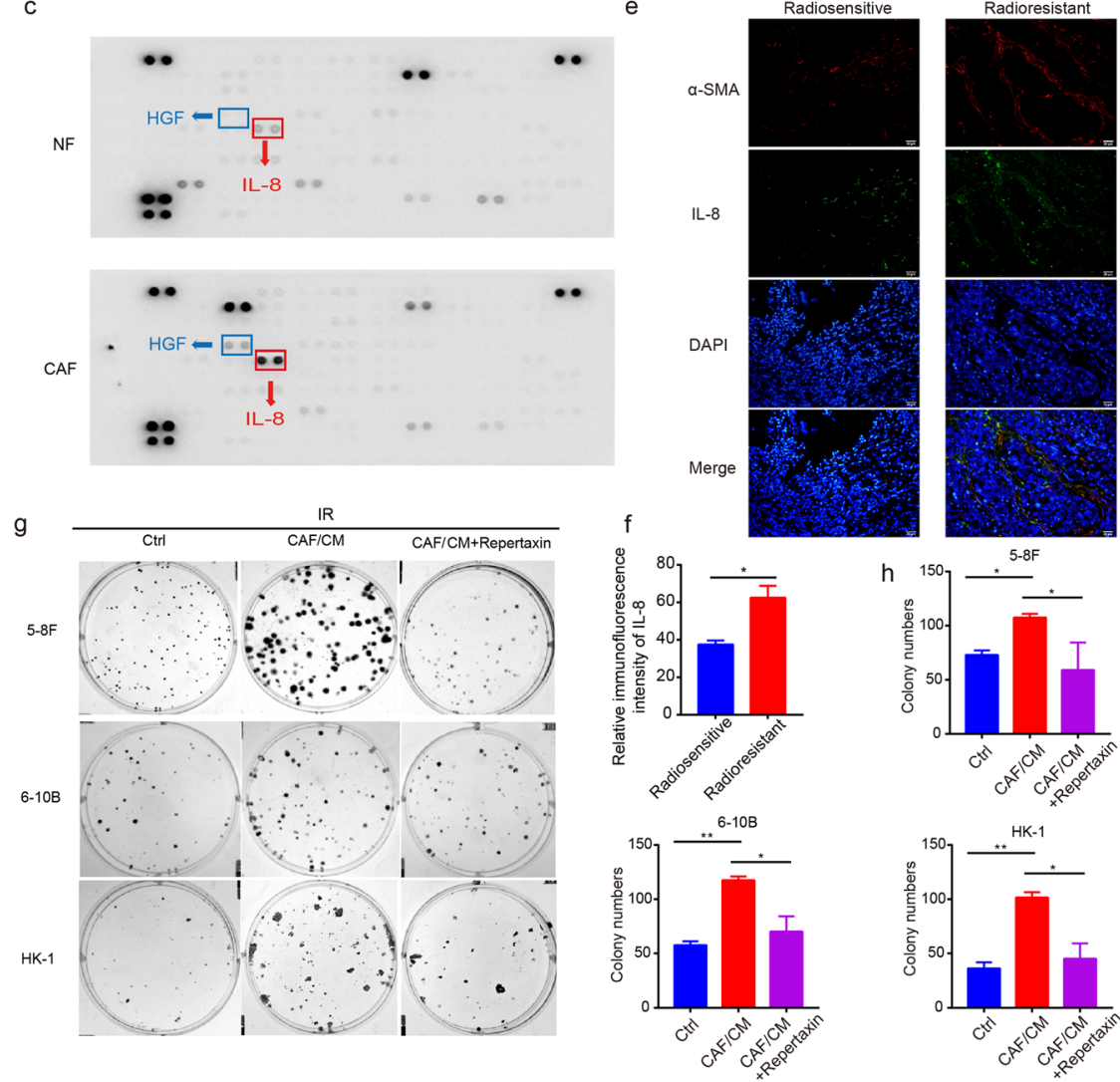

Fig. 2 CAFs secreted higher level of IL-8 than NFs. a and $\mathbf{b}$ CAFs promoted survival of NPC cells after irradiation. $\mathbf{c}$ and $\mathbf{d}$ Higher level of IL-8 were detected in the CAF supernatants and evaluated by real-time PCR. e and $\mathbf{f}$ Represented Immunofluorescence images of IL-8 and a-SMA in NPC tissues were shown. $\mathbf{g}$ and $\mathbf{h}$ Treatment with an IL-8 receptor antagonist $(10 \mu \mathrm{M})$ inhibited the proliferation of NPC cells after irradiation. * $P<0.05$; ${ }^{* *} P<0.01$; ${ }^{* *} P<0.001$; ${ }^{* * *} P<0.0001$, ns, no significance

exposure to irradiation, the survival of cancer cells was augmented under stimulation with CAF/CM, which was reversed when an NF- $\mathrm{kB}$ pathway inhibitor was added at a concentration of $2 \mu \mathrm{M}$ (Fig. 3c-e), indicating the requirement of the NF- $\mathrm{kB}$ pathway in promoting the recovery of NPC cells following irradiation.

\section{CAFs reduce DNA damage caused by irradiation}

Since irradiation is an effective therapeutic strategy, it mainly eliminates tumors by inducing DNA damage, including single strand and double strand brakes [32]. DNA damage repair was reported to be a frequently occurring event in radioresistant tumors [33]. The GSEA 

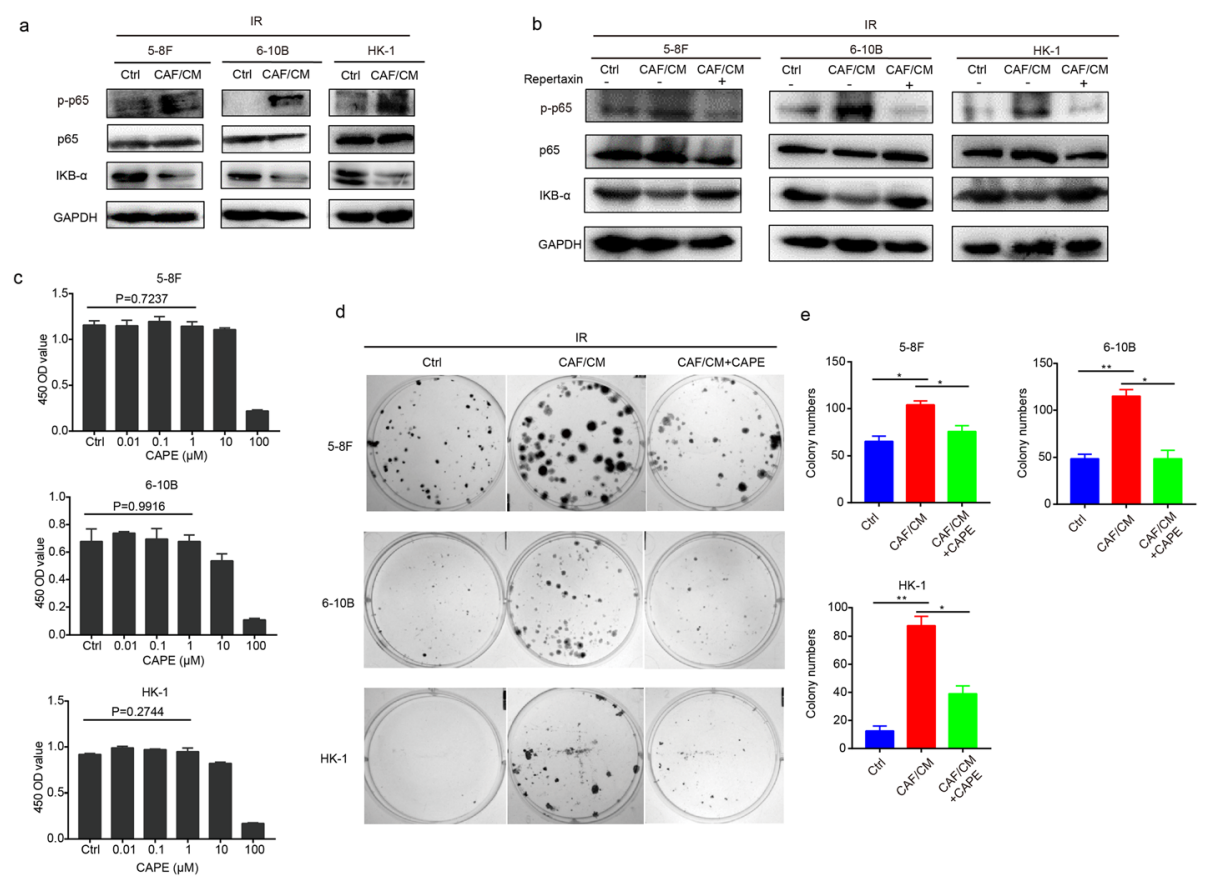

Fig. 3 CAFs activated the NF-KB pathway in irradiated NPC cells. a CAFs activated the NF-KB pathway in irradiated NPC cells. $\mathbf{b}$ Treatment with an IL-8 receptor antagonist inhibited activation of the NF-KB pathway in irradiated NPC cells. c The proliferation of NPC cell lines was evaluated by a CCK-8 assay under a wide-range of concentrations of CAPE. $\mathbf{d}$ and $\mathbf{e}$ A blockade of the NF-KB pathway with CAPE (2 $\mu \mathrm{M})$ inhibited the recovery of NPC cells after irradiation. * $P<0.05$; ${ }^{* *} P<0.01$; ${ }^{* *} P<0.001$; ${ }^{* * *} P<0.0001$, ns, no significance

results revealed an enrichment of DNA repair-related signaling pathways in radioresistant NPC tissue (Fig. 4a). Therefore, we speculated that CAFs could have an impact on DNA damage repair to promote tumor growth following irradiation. The results of the comet assay demonstrated that cells stimulated with CAF/CM after irradiation had fewer and shorter tails (Fig. $4 \mathrm{~b}$ and c), indicating the reduced level of DNA damage. Cultured with CAF/CM led to fewer $\gamma-\mathrm{H} 2 \mathrm{AX}$ foci and an IL-8 blockade or NF- $\mathrm{kB}$ pathway blocking could restore the expression of $\gamma-\mathrm{H} 2 \mathrm{AX}$ (Fig. 4d-g). Further, the activation of NF- $\kappa$ B pathway via TNF- $\alpha$ reduced the degree of DNA damage (Fig. 4h and i). All observations revealed that CAFs reduced the level of DNA damage via the IL8/NF- $\mathrm{kB}$ signaling pathway in tumor cells following irradiation.

\section{Tranilast inhibits CAFs functionality}

Accumulating evidence indicates that Tranilast is capable of inhibiting CAFs functionality [14]; however, little is known regarding whether Tranilast can impede the induction of radiation-resistance and attenuate CAF-induced NPC cell survival. Therefore, we first focused on the impact of Tranilast treatment on CAFs. As expected, $\alpha-S M A$ expression, a marker of CAFs activation, was significantly decreased following treatment with Tranilast (Fig. 5a).
Moreover, Tranilast inhibited CAFs viability and proliferation in a concentration-dependent manner (Fig. 5b).

Functionally, we detected the level of IL- 8 in CAFs treated with Tranilast. Similarly, the level of IL-8 mRNA was significantly down-regulated following an intervention with Tranilast compared to that of the control group (Fig. 5c). Moreover, Tranilast disrupted the activation of the NF- $k B$ pathway via down-regulation of phosphorylated p65 protein in tumor cells (Fig. $5 \mathrm{~d}$ ) and resulted in a larger degree of DNA damage (Fig. S5a - d). Next, CM from CAFs previously treated with or without Tranilast were collected to culture cancer cells after irradiation with $2 \mathrm{~Gy}$. The group stimulated with CM from CAFs ever-treated with Tranilast revealed decreased survival of cells after irradiation when compared with the control group (Fig. 5e and $\mathrm{f}$ ). Moreover, Tranilast also reversed the radioresistance characteristics induced by CAFs (Fig. $5 \mathrm{~g}$ and $\mathrm{h}$ ). In vivo, tumor cells mixed with CAFs were subcutaneously implanted into nude mice. After irradiation, tumors coinjected with CAFs grew faster than both co-injected Tranilast with CAFs group, and control group. This indicated that CAF plays a key role in promoting the development of irradiated tumors (Fig. 5i and j). Expression of $\alpha$-SMA staining in CAF co-injected group was also higher than that in the above two groups (Fig. 5k; Fig. S5e). All of the above results suggest that Tranilast inhibits the functional activity of CAFs to inactivate the NF- $\mathrm{B}$ p pathway, thereby 


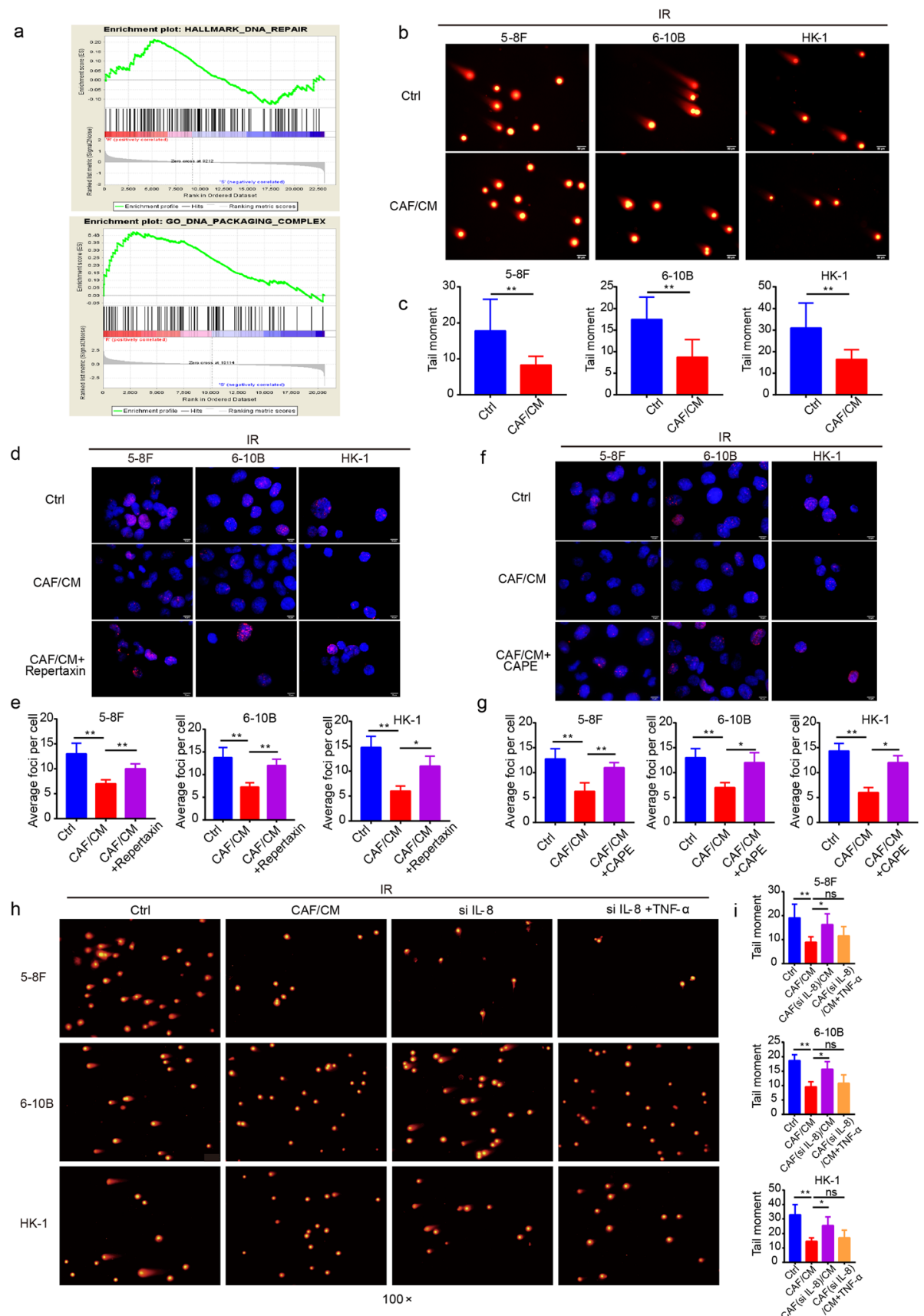

Fig. 4 CAFs reduced the level of DNA damage in NPC cells after irradiation. a GSEA of GSE48501 cell microarray and tissue microarray were conducted and pathways related to DNA damage and repair were enriched. $\mathbf{b}$ and $\mathbf{c}$ Comet assay showed that CAFs reduced the level of DNA damage in irradiated tumor cells. $\mathbf{d}$ and $\mathbf{e}$ Interruption of the IL-8 signaling pathway increased the distribution of $\gamma-\mathrm{H} 2 \mathrm{AX}$ foci post-irradiation. $\mathbf{f}$ and $\mathbf{g}$ A blockade of the NF-KB pathway increased $\gamma-\mathrm{H} 2 \mathrm{AX}$ foci in irradiated NPC cells. $\mathbf{h}$ and $\mathbf{i}$ A blockade of the IL-8/NF-KB pathway increased the level of DNA damage in irradiated NPC cells. ${ }^{*} P<0.05$; ${ }^{* *} P<0.01$; ${ }^{* *} P<0.001$; ${ }^{* * *} P<0.0001$, ns, no significance

leading to increased cancer cell death and sensitization of NPC cells to irradiation (Fig. 6).

\section{Discussion}

NPC is an EBV-related cancer, which is especially prevalent in Guangdong province, China [34]. Clinically, the challenges following relapse after irradiation are unavoidable and one of the primary reasons for the poor prognosis of cancer treatment $[16,35]$. However, the potential mechanisms for tumor relapse are complex and remain poorly understood. NPC is a type of solid carcinoma with several elements of the TME. To date, the 


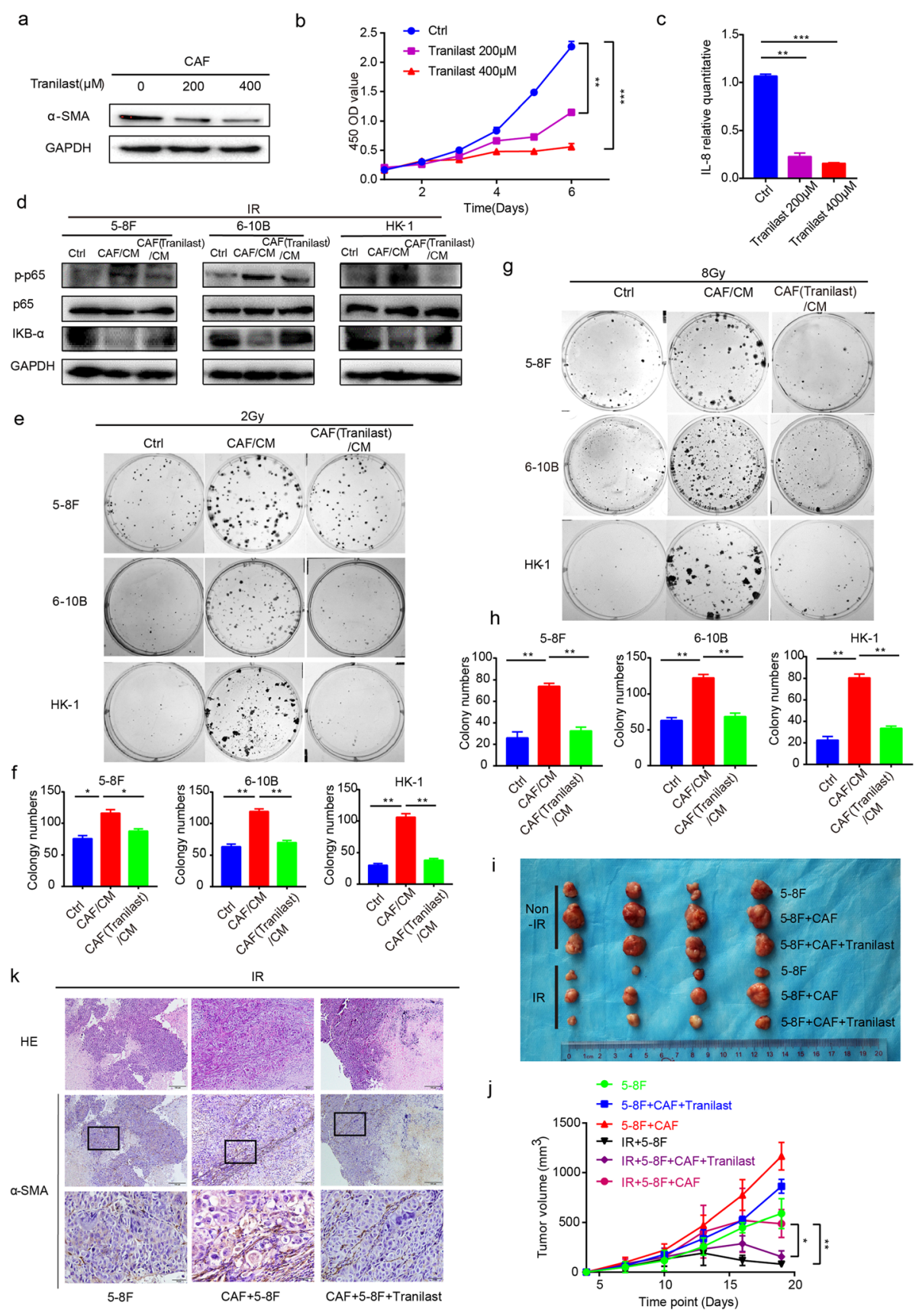

Fig. 5 Tranilast treatment inhibited CAFs activity and functionality. a Treatment with Tranilast inhibited the activation of CAFs. b Tranilast inhibited the proliferation of CAFs. c Tranilast down-regulated IL-8 at the transcription level. $\mathbf{d}$ Tranilast restricted the activation of the NF-KB pathway in NPC cells. e and $\mathbf{f}$ Tranilast restricted the proliferation of NPC cells after irradiation. $\mathbf{g}$ and $\mathbf{h}$ Tranilast restored the radiosensitivity of NPC cells. $\mathbf{i}$ and $\mathbf{j}$ Tranilast inhibited the proliferation of irradiated NPC cells in vivo. $\mathbf{k}$ Represented images of HE staining and a-SMA staining of in vivo experiment were shown. ${ }^{*} P<0.05 ;{ }^{* *} P<0.01$; ${ }^{* *} P<0.001$; ${ }^{* * *} P<0.0001$, ns, no significance

TME has gained increasing attention as a nutrient source required for cancer aggressiveness. Current research has mainly focused on the TME rather than only on the tumors, emphasizing the importance of the TME in tumor progression.
The TME is composed of cellular and non-cellular components and has been reported to promote tumor recurrence following irradiation $[13,36]$. Of the plethora of cell types within the TME, CAFs are predominant, present in abundance and exhibiting distinct properties 


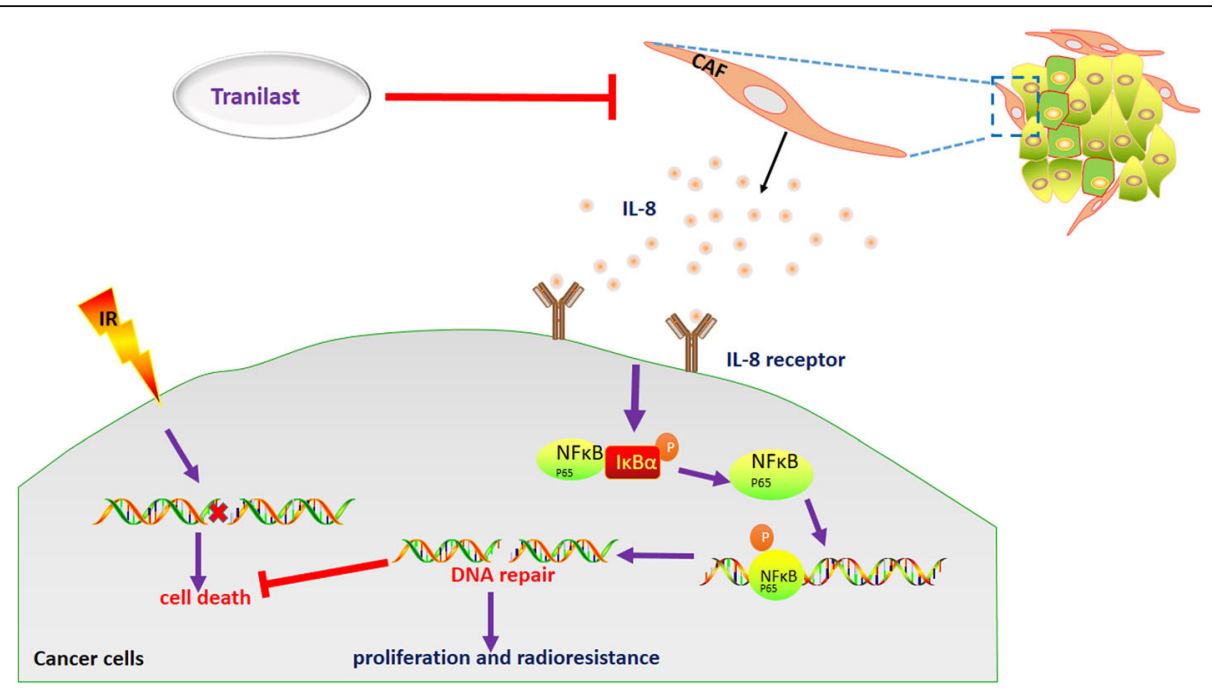

Fig. 6 CAFs promoted the survival of irradiated NPC cells via the NF-KB pathway. Irradiation kills cancer cells via DNA damage. CAFs within TME promoted irradiated cancer cell survival by secretion of IL-8 to activate NF-KB signaling pathway, thus to enhance broken DNA repair and induced formation of radioresistance. Tranilast sensitized cancer cells to irradiation through the suppression of CAFs functionally, thus promoted irradiation-induced cell death

in numerous cancers [37]. In head and neck cancer, a high degree of CAF infiltration was reported to accelerate tumor progression via the regulation of metabolism activity [6]. Moreover, CAFs resident in NPC have been reported to promote tumor migration and invasion, thereby contribute to a poor prognosis. Despite these findings, studies involving CAFs and irradiation in NPC are inadequate. According to our findings, there was substantial CAF infiltration in the radioresistant NPC tissue compared with radiosensitive NPC tissue. Generally, tumors with abundant stromal components are usually stiff. This finding was consistent with the observation that patients with poor clinical efficacy usually present with stiff tumor [38]. Moreover, CAFs were found to both enhance survival and induce radioresistance in irradiated NPC cells, illustrating the multifunctionality of CAFs within the TME for NPC. As previously documented, CAFs modified the TME primarily through the continuous secretion of inflammatory cytokines essential for tumor proliferation, migration, invasion, metastasis and, resistance to treatment (e.g., vascular endothelial growth factor [VEGF] and HGF) [39-41]. Pathways that respond to irradiation, including the Wnt $/ \beta$-catenin, $\beta 1$-integrin, and P38 signaling pathways, have been identified [10, 42, 43]. In addition, IL- 8 and HGF have been reported to be secreted by CAFs to promote HNSCC aggressiveness and were associated with worse prognosis $[44,45]$. Based on our research, CAFs were found to enhance cell proliferation after irradiation via the secretion of IL-8 to trigger NF- $\mathrm{kB}$ activation with up-regulation of p-p65 in NPC cells. Disruption of NF- $\kappa B$ signaling impaired the recovery of tumor cells after irradiation promoted by CAFs.

In general, radiation can destroy DNA and result in damage ranging from nucleotide lesions to single- and double-strand breaks (SSBs and DSBs) [46], thereby killing tumor cells. The underlying mechanisms responsible for radioresistance are highly variable, among which include DNA damage repair $[47,48]$. Recently, CAFs have been reported to assist cancer cell recovery from irradiation through autophagy, which is related to the DNA damage repair pathway [13]. Therefore, we hypothesized that CAFs could reduce the level of DNA damage to NPC cells following irradiation. Detection of the $\gamma$ H2AX protein that participated in the process of DNA damage $[49,50]$ showed that CAFs actually impaired tumor cell DNA damage. Moreover, NF- $\mathrm{kB}$ signaling was reported to engage in irradiation resistance in glioblastoma and pathogenesis of several cancer [51, 52]. Accordingly, we showed that a blockade of IL-8/NF- KB signaling interrupted NPC survival after irradiation, emphasizing the significance of the NF-kB pathway during the process of radioresistance.

Even though CAFs can have multiple cells-of-origin, such as stellate cells, mesenchymal stem cells, mesothelial cells and several other potential sources, resident fibroblasts are considered to be the most important source of CAFs [53]. In our study, CAFs were proved to promote irradiated tumor proliferation when coinjection with tumor cells in vivo. Similarly, it was reported that CAFs co-injected with tumor cells could be detected and persisted in tumor tissues [54, 55]. 
Nonetheless, it was also demonstrated by several studies that CAFs in xenograft tumors disappear shortly after co-injection [56]. We speculated an early enhancement of proliferation in tumor cells when co-injection with CAFs. This effect could persist for an indicated time once the critical signaling pathways were activated in tumor cells, even though injected CAFs gradually disappeared later. Insights into the mechanisms require further investigation.

Due to the predominant abundance within TME and the versatile properties essential for tumorigenesis, CAFs were considered to be a potential target cell type for therapeutic options. Previous studies have implied that Tranilast, a CAF inhibitor, could inhibit CAF proliferation and activation, as well as suppress the release of bioactive cytokines produced by CAFs [57]. Consistent with these reports, our data demonstrated that Tranilast inhibited CAF proliferation and reduced CAF activation as evidenced by lower $\alpha$-SMA expression. Functionally, Tranilast impeded NPC cell growth after irradiation and restored the radiosensitivity of tumor cells against CAFs. Mechanically, Tranilast blocked the activation of NF- $\mathrm{kB}$ pathway and reversed the DNA damage induced by irradiation. All data indicate that Tranilast may be a promising inhibitor against CAFs to accelerate NPC elimination after irradiation. And the potential function of Tranilast to sensitize NPC to irradiation needs further research in the future.

\section{Conclusions}

In summary, our findings revealed the importance of CAFs in NPC progression following irradiation by enhancing the survival of tumor cells, which promotes radioresistance. Mechanistically, IL-8 secretion by CAFs activated the NF- $\mathrm{KB}$ pathway in NPC, thus reducing the level of DNA damage caused by irradiation. Importantly, treatment with Tranilast inhibited CAF functionality and sensitized the tumor cells to irradiation; however, additional clinical samples are warranted to further validate the relationship among CAFs, radioresistance in tumor cells.

\section{Supplementary Information}

The online version contains supplementary material available at https://doi. org/10.1186/s13046-021-01878-x.

Additional file 1: Table1. Patient and tumor characteristics.

Additional file 2. List of differential expression genes.

Additional file 3: Figure S1. Infiltration of CAFs in NPC tissue. $a$ and $b$ Expression of FAP was higher in radioresistant NPC than radiosensitive NPC tissue. C Represented images of a-SMA and FAP staining of one NPC donor tissue used for primary culture were shown. ${ }^{*} P<0.05$; ${ }^{*} P<$ 0.01 ; ${ }^{* *} P<0.001$; ${ }^{* * *} P<0.0001$, ns, no significance.

Additional file 4: Figure S2. CAFs promoted the recovery of irradiated tumor cells via IL-8. $a$ and $b$ IL-8 promoted the recovery of tumor cells after irradiation. c High levels of HGF were verified in CAFs. d and e HGF failed to significantly promote the recovery of tumor cells after irradiation. $f$ The efficiency of knocking down IL-8 was verified by real-time PCR. $g$ and $h$ Knock-down of IL-8 in CAFs inhibited the survival of NPC cells after irradiation. ${ }^{*} P<0.05$; ** $P<0.01$; ** $P<0.001$; *** $P<0.0001$, ns, no significance.

Additional file 5: Figure S3. CAF promoted the survival of irradiated tumor cells. a The proliferation of NPC cell lines was evaluated by CCK-8 assay under a diverse range of Repertaxin concentrations. b CAFs produced a higher amount of lactate than NFs. $c$ and d Disruption of lactate production with a lactate inhibitor (DCA) failed to promote the survival of irradiated tumor cells. ${ }^{*} P<0.05$; ${ }^{* *} P<0.01$; ${ }^{* *} P<0.001$; ${ }^{* * *} P<0.0001$, ns, no significance.

Additional file 6: Figure S4. The NF-KB pathway was activated in radioresistant NPC cells and tissues. $a$ and $b$ The NF-KB pathway was substantially up-regulated in radioresistant cells and tissues. c Heatmap of differentially regulated genes in the tissue microarray was shown. $d$ and e The 5-8F IRR cell line was established and a survival curve at different dose was created. $f$ and $g$ The NF-kB pathway was significantly activated in the 5-8F IRR cell line, which was verified by western blot. ${ }^{*} P<0.05$; ** $P<0.01$; ${ }^{* * *} P<0.001{ }^{* * * *} P<0.0001$, ns, no significance.

Additional file 7: Figure S5. Tranilast restored irradiation-induced DNA damage in irradiated tumor cells. a and b Comet assay showed that Tranilast treatment reversed the DNA repair promoted by CAFs. $c$ and $d$ Tranilast restored the distribution of $\gamma-\mathrm{H} 2 \mathrm{AX}$ foci in irradiated tumor cells. e Analysis of a-SMA staining of in vivo experiment.* $P<0.05$; ${ }^{* *} P<0.01$; *** $P<0.001$; *** $P<0.0001$, ns, no significance.

\section{Abbreviations}

NPC: Nasopharyngeal carcinoma; HNSCC: Head and neck squamous cell carcinoma; EBV: Epstein-Barr virus; CAF: Cancer-associated fibroblast; NF: Normal fibroblast; RSI: Radiosensitivity index; IRR: Irradiation resistant; IR: Irradiation; a-SMA: Alpha smooth muscle Actin; FAP: Fibroblast activated protein; VEGF: Vascular endothelial growth factor; NF-KB: Nuclear factor kappa-B; IL-8: Interleukin 8; HGF: Hepatocyte growth factor; RTqPCR: Quantitative real-time polymerase chain reaction; GSEA: Gene set enrichment analysis; DSBs: Double-strand breaks; SSBs: Single-strand breaks

\section{Acknowledgements}

We thank Department of Otolaryngology, Department of Stomatology, Nanfang Hospital for providing clinical samples.

\section{Authors' contributions}

Huang Weiqiang did most of experiments and wrote the original draft. Zhang Longshan and Yang Mi took part in cell culture and western blot assay. Wu Xixi, Wang Xiaoqing and Wang Yin took part in IHC assay. Huang Wenqi, Yuan Lu and Wang Zici supported to optimize experimental protocols. Pan Hua and Liao Liwei took part in in vivo study. Zhang Longshan, Liang Huazhen and Li Shaoqun provided valuable suggestions and helped revise the manuscript. Pan Hua, Wu Yuting and Huang Jihong took part in sample collection. Guan Jian and Liu Laiyu provided funding support. All authors read and approved the final manuscript.

\section{Funding}

The research was funded by National Natural Science Foundation of China (NO. 81602685, 81672992); Clinical Research Startup Program of Southern Medical University by High-level University Construction Funding of Guangdong Provincial Department of Education (LC2019ZD008, LC2018CR021); Health \& Medical Collaborative Innovation Project of Guangzhou City, China (201803040003); the Natural Science Foundation of Guangdong Province (NO. 2017A030313486).

\section{Availability of data and materials}

All data that can prove the conclusion of this article are included in the article.

\section{Ethics approval and consent to participate}

This work was approved by the Ethics Committee of Nanfang Hospital of Southern Medical University, and all participants provided written informed 
consent prior to surgery. The study was in accordance with provisions of the Declaration of Helsinki.

\section{Consent for publication}

All authors consent this manuscript to be published.

\section{Competing interests}

The authors declare that they have no competing interests.

\begin{abstract}
Author details
'Department of Radiation Oncology, Nanfang Hospital, Southern Medical University, Guangzhou, Guangdong, China. ${ }^{2}$ Chronic Airways Diseases Laboratory, Department of Respiratory and Critical Care Medicine, Nanfang Hospital, Southern Medical University, Guangzhou, Guangdong, China. ${ }^{3}$ Department of Obstetrics and Gynecology, The First Affiliated Hospital of Guangzhou Medical University, Guangzhou, Guangdong, China. ${ }^{4}$ Department of Oncology, Maoming People's Hospital, Maoming, Guangdong, China. ${ }^{5}$ Department of Radiation Oncology, Guangdong 999 Brain Hospital, Guangzhou, Guangdong, China.
\end{abstract}

Received: 5 November 2020 Accepted: 14 February 2021

Published online: 01 March 2021

\section{References}

1. Chua MLK, Wee JTS, Hui EP, ATC C. Nasopharyngeal carcinoma. Lancet. 2016:387(10022):1012-24

2. Bray F, Ferlay J, Soerjomataram I, Siegel RL, Torre LA, Jemal A. Global cancer statistics 2018: GLOBOCAN estimates of incidence and mortality worldwide for 36 cancers in 185 countries. CA Cancer J Clin. 2018:68(6):394-424.

3. Yeh SA, Tang Y, Lui CC, Huang YJ, Huang EY. Treatment outcomes and late complications of 849 patients with nasopharyngeal carcinoma treated with radiotherapy alone. Int J Radiat Oncol Biol Phys. 2005;62(3):672-9.

4. Wang WJ, Wu SP, Liu JB, Shi YS, Huang X, Zhang QB, Yao KT. MYC regulation of $\mathrm{CHK} 1$ and $\mathrm{CHK} 2$ promotes radioresistance in a stem celllike population of nasopharyngeal carcinoma cells. Cancer Res. 2013; 73(3):1219-31

5. DeBerardinis RJ. Tumor microenvironment, metabolism, and immunotherapy. N Engl J Med. 2020;382(9):869-71.

6. Kumar D, New J, Vishwakarma V, Joshi R, Enders J, Lin F, Dasari S, Gutierrez WR, Leef G, Ponnurangam S, Chavan H, Ganaden L, Thornton MM, Dai H Tawfik O, Straub J, Shnayder Y, Kakarala K, Tsue T, Girod DA, Van Houten B, Anant S, Krishnamurthy P. Thomas SM. Cancer-associated fibroblasts drive glycolysis in a targetable signaling loop implicated in head and neck squamous cell carcinoma progression. Cancer Res. 2018;78(14):3769-82.

7. Wang HC, Chan LP, Cho SF. Targeting the Immune Microenvironment in the Treatment of Head and Neck Squamous Cell Carcinoma. Front Oncol. 2019;9:1084.

8. Wheeler SE, Shi H, Lin F, Dasari S, Bednash J, Thorne S, Watkins S, Joshi R, Thomas SM. Enhancement of head and neck squamous cell carcinoma proliferation, invasion, and metastasis by tumor-associated fibroblasts in preclinical models. Head Neck. 2014;36(3):385-92.

9. Chu TY, Yang JT, Huang TH, Liu HW. Crosstalk with cancer-associated fibroblasts increases the growth and radiation survival of cervical cancer cells. Radiat Res. 2014;181(5):540-7.

10. Li D, Qu C, Ning Z, Wang H, Zang K, Zhuang L, Chen L, Wang P, Meng Z. Radiation promotes epithelial-to-mesenchymal transition and invasion of pancreatic cancer cell by activating carcinoma-associated fibroblasts. Am J Cancer Res. 2016;6(10):2192-206.

11. Ferris RL, Blumenschein G Jr, Fayette J, Guigay J, Colevas AD, Licitra L, Harrington K, Kasper S, Vokes EE, Even C, Worden F, Saba NF, Iglesias Docampo LC, Haddad R, Rordorf T, Kiyota N, Tahara M, Monga M, Lynch M, Geese WJ, Kopit J, Shaw JW, Gillison ML. Nivolumab for recurrent squamous-cell carcinoma of the head and neck. N Engl J Med. 2016;375(19): 1856-67.

12. Seiwert TY, Burtness B, Mehra R, Weiss J, Berger R, Eder JP, Heath $K$, McClanahan T, Lunceford J, Gause C, Cheng JD, Chow LQ. Safety and clinical activity of pembrolizumab for treatment of recurrent or metastatic squamous cell carcinoma of the head and neck (KEYNOTE-012): an openlabel, multicentre, phase 1b trial. Lancet Oncol. 2016;17(7):956-65.
13. Wang Y, Gan G, Wang B, Wu J, Cao Y, Zhu D, Xu Y, Wang X, Han H, Li X, Ye M, Zhao J, Mi J. Cancer-associated Fibroblasts Promote Irradiated Cancer Cell Recovery Through Autophagy. EBioMedicine. 2017;17:45-56.

14. Ohshio Y, Hanaoka J, Kontani K, Teramoto K. Tranilast inhibits the function of cancer-associated fibroblasts responsible for the induction of immune suppressor cell types. Scand J Immunol. 2014;80(6):408-16.

15. Khamaisi M, Katagiri S, Keenan H, Park K, Maeda Y, Li Q, Qi W, Thomou T, Eschuk D, Tellechea A, Veves A, Huang C, Orgill DP, Wagers A, King GL. PKCdelta inhibition normalizes the wound-healing capacity of diabetic human fibroblasts. J Clin Invest. 2016;126(3):837-53.

16. Li G, Liu Y, Su Z, Ren S, Zhu G, Tian Y, Qiu Y. MicroRNA-324-3p regulates nasopharyngeal carcinoma radioresistance by directly targeting WNT2B. Eur J Cancer. 2013:49(11):2596-607.

17. Wang N, Wang Q, Tang H, Zhang F, Zheng Y, Wang S, Zhang J, Wang Z, Xie $X$. Direct inhibition of ACTN4 by ellagic acid limits breast cancer metastasis via regulation of beta-catenin stabilization in cancer stem cells. J Exp Clin Cancer Res. 2017;36(1):172.

18. Tang XR, Li YQ, Liang SB, Jiang W, Liu F, Ge WX, Tang LL, Mao YP, He QM, Yang XJ, Zhang Y, Wen X, Zhang J, Wang YQ, Zhang PP, Sun Y, Yun JP, Zeng J, Li L, Liu LZ, Liu N, Ma J. Development and validation of a gene expression-based signature to predict distant metastasis in locoregionally advanced nasopharyngeal carcinoma: a retrospective, multicentre, cohort study. Lancet Oncol. 2018;19(3):382-93.

19. Robb R, Yang L, Shen C, Wolfe AR, Webb A, Zhang X, Vedaie M, Saji M, Jhiang S, Ringel MD, Williams TM. Inhibiting BRAF oncogene-mediated Radioresistance effectively Radiosensitizes BRAF(V600E)-mutant thyroid Cancer cells by constraining DNA double-Strand break repair. Clin Cancer Res. 2019:25(15):4749-60.

20. Racle J, de Jonge K, Baumgaertner P, Speiser DE, Gfeller D. Simultaneous enumeration of cancer and immune cell types from bulk tumor gene expression data. Elife. 2017;6. https://doi.org/10.7554/eLife.26476.

21. Estrada-Bernal A, Chatterjee M, Haque SJ, Yang L, Morgan MA, Kotian S, Morrell D, Chakravarti A, Williams TM. MEK inhibitor GSK1120212-mediated radiosensitization of pancreatic cancer cells involves inhibition of DNA double-strand break repair pathways. Cell Cycle. 2015;14(23):3713-24.

22. Jiao Q, Liu C, Li W, Li W, Fang F, Qian Q, Zhang X. Programmed death-1 ligands 1 and 2 expression in cutaneous squamous cell carcinoma and their relationship with tumour- infiltrating dendritic cells. Clin Exp Immunol. 2017; 188(3):420-9.

23. Yang $M$, Huang $W$, Sun $Y$, Liang $H$, Chen $M$, Wu X, Wang $X$, Zhang $L$, Cheng $X$, Fan $Y$, Pan H, Chen L, Guan J. Prognosis and modulation mechanisms of COMMD6 in human tumours based on expression profiling and comprehensive bioinformatics analysis. Br J Cancer. 2019;121(8):699-709.

24. Huang C, Lu H, Li J, Xie X, Fan L, Wang D, Tan W, Wang Y, Lin Z, Yao T. SOX2 regulates radioresistance in cervical cancer via the hedgehog signaling pathway. Gynecol Oncol. 2018;151(3):533-41.

25. Sheng $H$, Huang $Y$, Xiao $Y$, Zhu Z, Shen $M$, Zhou P, Guo Z, Wang J, Wang H, Dai W, Zhang W, Sun J, Cao C. ATR inhibitor AZD6738 enhances the antitumo activity of radiotherapy and immune checkpoint inhibitors by potentiating the tumor immune microenvironment in hepatocellular carcinoma. J Immunother Cancer. 2020:8(1). https://doi.org/10.1136/jitc-2019-000340.

26. Qin X, Guo H, Wang X, Zhu X, Yan M, Wang X, Xu Q, Shi J, Lu E, Chen W, Zhang J. Exosomal miR-196a derived from cancer-associated fibroblasts confers cisplatin resistance in head and neck cancer through targeting CDKN1B and ING5. Genome Biol. 2019;20(1):12.

27. Avgustinova A, Iravani M, Robertson D, Fearns A, Gao Q, Klingbeil P, Hanby AM, Speirs V, Sahai E, Calvo F, Isacke CM. Tumour cell-derived Wnt7a recruits and activates fibroblasts to promote tumour aggressiveness. Nat Commun. 2016;7:10305.

28. Dourado MR, Korvala J, Astrom P, De Oliveira CE, Cervigne NK, Mofatto LS, Campanella Bastos D, Pereira Messetti AC, Graner E, Paes Leme AF, Coletta $\mathrm{RD}$, Salo T. Extracellular vesicles derived from cancer-associated fibroblasts induce the migration and invasion of oral squamous cell carcinoma. Extracell Vesicles. 2019:8(1):1578525.

29. Mueller L, Goumas FA, Affeldt M, Sandtner S, Gehling UM, Brilloff S, Walter J, Karnatz N, Lamszus K, Rogiers X, Broering DC. Stromal fibroblasts in colorectal liver metastases originate from resident fibroblasts and generate an inflammatory microenvironment. Am J Pathol. 2007;171(5):1608-18.

30. Wojtkowiak JW, Verduzco D, Schramm KJ, Gillies RJ. Drug resistance and cellular adaptation to tumor acidic pH microenvironment. Mol Pharm. 2011; 8(6):2032-8. 
31. Greijer AE, de Jong MC, Scheffer GL, Shvarts A, van Diest PJ, van der Wall E. Hypoxia-induced acidification causes mitoxantrone resistance not mediated by drug transporters in human breast cancer cells. Cell Oncol. 2005;27(1):43-9.

32. Zhang Q, Green MD, Lang X, Lazarus J, Parsels JD, Wei S, Parsels LA, Shi J, Ramnath N, Wahl DR. Pasca Di Magliano M., Frankel T. L., Kryczek I., lei Y. L., Lawrence T. S., Zou W., Morgan M. A. Inhibition of ATM increases interferon signaling and sensitizes pancreatic Cancer to immune checkpoint blockade therapy. Cancer Res. 2019;79(15):3940-51.

33. Visvader JE, Lindeman GJ. Cancer stem cells in solid tumours: accumulating evidence and unresolved questions. Nat Rev Cancer. 2008;8(10):755-68.

34. Tian YM, Tian YH, Zeng L, Liu S, Guan Y, Lu TX, Han F. Prognostic model for survival of local recurrent nasopharyngeal carcinoma with intensitymodulated radiotherapy. Br J Cancer. 2014;110(2):297-303.

35. Sun Q, Liu T, Zhang T, Du S, Xie GX, Lin X, Chen L, Yuan Y. MiR-101 sensitizes human nasopharyngeal carcinoma cells to radiation by targeting stathmin 1. Mol Med Rep. 2015;11(5):3330-6.

36. Barker HE, Paget JT, Khan AA, Harrington KJ. The tumour microenvironment after radiotherapy: mechanisms of resistance and recurrence. Nat Rev Cancer. 2015;15(7):409-25.

37. Peltanova B, Raudenska M, Masarik M. Effect of tumor microenvironment on pathogenesis of the head and neck squamous cell carcinoma: a systematic review. Mol Cancer. 2019;18(1):63.

38. Wei SC, Fattet L, Tsai JH, Guo Y, Pai VH, Majeski HE, Chen AC, Sah RL, Taylor SS, Engler AJ, Yang J. Matrix stiffness drives epithelial-mesenchymal transition and tumour metastasis through a TWIST1-G3BP2 mechanotransduction pathway. Nat Cell Biol. 2015;17(5):678-88.

39. Jia CC, Wang TT, Liu W, Fu BS, Hua X, Wang GY, Li TJ, Li X, Wu XY, Tai Y, Zhou J, Chen GH, Zhang Q. Cancer-associated fibroblasts from hepatocellular carcinoma promote malignant cell proliferation by HGF secretion. PLoS One. 2013;8(5):e63243

40. Bello IO, Vered M, Dayan D, Dobriyan A, Yahalom R, Alanen K, Nieminen P, Kantola S, Laara E, Salo T. Cancer-associated fibroblasts, a parameter of the tumor microenvironment, overcomes carcinoma-associated parameters in the prognosis of patients with mobile tongue cancer. Oral Oncol. 2011; 47(1):33-8.

41. Calon A, Tauriello DV, Batlle E. TGF-beta in CAF-mediated tumor growth and metastasis. Semin Cancer Biol. 2014;25:15-22.

42. Mantoni TS, Lunardi S, Al-Assar O, Masamune A, Brunner TB. Pancreatic stellate cells radioprotect pancreatic cancer cells through beta1-integrin signaling. Cancer Res. 2011;71(10):3453-8.

43. Han PB, Ji XJ, Zhang M, Gao LY. Upregulation of IncRNA LINC00473 promotes radioresistance of HNSCC cells through activating Wnt/betacatenin signaling pathway. Eur Rev Med Pharmacol Sci. 2018;22(21): 7305-13.

44. New J, Arnold L, Ananth M, Alvi S, Thornton M, Werner L, Tawfik O, Dai H, Shnayder Y, Kakarala K, Tsue TT, Girod DA, Ding WX, Anant S, Thomas SM. Secretory autophagy in Cancer-associated fibroblasts promotes head and neck Cancer progression and offers a novel therapeutic target. Cancer Res. 2017;77(23):6679-91.

45. Le QT, Fisher R, Oliner KS, Young RJ, Cao H, Kong C, Graves E, Hicks RJ, McArthur GA, Peters L, O'Sullivan B, Giaccia A, Rischin D. Prognostic and predictive significance of plasma HGF and IL-8 in a phase III trial of chemoradiation with or without tirapazamine in locoregionally advanced head and neck cancer. Clin Cancer Res. 2012;18(6):1798-807.

46. McLaughlin M, Patin EC, Pedersen M, Wilkins A, Dillon MT, Melcher AA, Harrington KJ. Inflammatory microenvironment remodelling by tumour cells after radiotherapy. Nat Rev Cancer. 2020;20(4):203-17.

47. Shimura T, Ochiai Y, Noma N, Oikawa T, Sano Y, Fukumoto M. Cyclin D1 overexpression perturbs DNA replication and induces replication-associated DNA double-strand breaks in acquired radioresistant cells. Cell Cycle. 2013; 12(5):773-82.

48. Teng K, Zhang Y, Hu X, Ding Y, Gong R, Liu L. Nimotuzumab enhances radiation sensitivity of NSCLC $\mathrm{H} 292$ cells in vitro by blocking epidermal growth factor receptor nuclear translocation and inhibiting radiationinduced DNA damage repair. Onco Targets Ther. 2015;8:809-18.

49. Rogakou EP, Pilch DR, Orr AH, Ivanova VS, Bonner WM. DNA doublestranded breaks induce histone H2AX phosphorylation on serine 139. J Biol Chem. 1998:273(10):5858-68.

50. Yuan J, Adamski R, Chen J. Focus on histone variant H2AX: to be or not to be. FEBS Lett. 2010:584(17):3717-24.
51. KPL B, Balasubramaniyan V, Vaillant B, Ezhilarasan R, Hummelink K, Hollingsworth F, Wani K, Heathcock L, James JD, Goodman LD, Conroy S, Long L, Lelic N, Wang S, Gumin J, Raj D, Kodama Y, Raghunathan A, Olar A, Joshi K, Pelloski CE, Heimberger A, Kim SH, Cahill DP, Rao G, WFA DD, HWGM B, Phillips HS, Nakano I, Lang FF, Colman H, Sulman EP, Aldape K. Mesenchymal differentiation mediated by NF-kappaB promotes radiation resistance in glioblastoma. Cancer Cell. 2013;24(3):331-46.

52. Zha L, Chen J, Sun S, Mao L, Chu X, Deng H, Cai J, Li X, Liu Z, Cao W. Soyasaponins can blunt inflammation by inhibiting the reactive oxygen species-mediated activation of PI3K/Akt/NF-kB pathway. PLoS One. 2014; 9(9):e107655.

53. Yang $X$, Hao J, Mao $Y$, Jin ZQ, Cao R, Zhu CH, Liu XH, Liu C, Ding XL, Wang XD, Chen D, Wu XZ. bFGF promotes migration and induces Cancer-associated fibroblast differentiation of mouse bone Mesenchymal stem cells to promote tumor growth. Stem Cells Dev. 2016;25(21):1629-39.

54. Kashima H, Noma K, Ohara T, Kato T, Katsura Y, Komoto S, Sato H, Katsube R, Ninomiya T, Tazawa H, Shirakawa Y, Fujiwara T. Cancer-associated fibroblasts (CAFs) promote the lymph node metastasis of esophageal squamous cell carcinoma. Int J Cancer. 2019;144(4):828-40.

55. McDonald LT, Russell DL, Kelly RR, Xiong Y, Motamarry A, Patel RK, Jones JA, Watson PM, Turner DP, Watson DK, Soloff AC, Findlay VJ, LaRue AC. Hematopoietic stem cell-derived cancer-associated fibroblasts are novel contributors to the pro-tumorigenic microenvironment. Neoplasia. 2015; 17(5):434-48.

56. Shen K, Luk S, Elman J, Murray R, Mukundan S, Parekkadan B. Suicide GeneEngineered Stromal Cells Reveal a Dynamic Regulation of Cancer Metastasis. Sci Rep. 2016;6:21239. https://doi.org/10.1038/srep21239.

57. Darakhshan S, Pour AB. Tranilast: a review of its therapeutic applications. Pharmacol Res. 2015;91:15-28.

\section{Publisher's Note}

Springer Nature remains neutral with regard to jurisdictional claims in published maps and institutional affiliations.

Ready to submit your research? Choose BMC and benefit from:

- fast, convenient online submission

- thorough peer review by experienced researchers in your field

- rapid publication on acceptance

- support for research data, including large and complex data types

- gold Open Access which fosters wider collaboration and increased citations

- maximum visibility for your research: over $100 \mathrm{M}$ website views per year

At $\mathrm{BMC}$, research is always in progress.

Learn more biomedcentral.com/submissions 